\title{
Strategy to Overcome Barriers of Rainwater Harvesting, Case Study Tanzania
}

\author{
Tulinave Burton Mwamila1 ${ }^{*}$, Moo Young Han'2, Zacharia Katambara3 \\ ${ }^{1}$ Department of Rural Water Supply, Ministry of Water and Irrigation, Dar es Salaam, Tanzania \\ ${ }^{2}$ Department of Civil and Environmental Engineering, Seoul National University, Seoul, South Korea \\ ${ }^{3}$ Department of Built Environment Engineering, Mbeya University of Science and Technology, Mbeya, Tanzania \\ Email: *mtulinave@gmail.com
}

How to cite this paper: Mwamila, T.B., Han, M.Y. and Katambara, Z. (2016) Strategy to Overcome Barriers of Rainwater Harvesting, Case Study Tanzania. Journal of Geoscience and Environment Protection, 4, 13-23.

http://dx.doi.org/10.4236/gep.2016.49002

Received: August 6, 2016

Accepted: September 9, 2016

Published: September 12, 2016

Copyright $\odot 2016$ by authors and Scientific Research Publishing Inc. This work is licensed under the Creative Commons Attribution International License (CC BY 4.0).

http://creativecommons.org/licenses/by/4.0/

\begin{abstract}
There are socio-technological challenges towards extension of the application of rainwater harvesting $(\mathrm{RWH})$ practices in developing countries. An attempt to address this was done using the Mnyundo Primary School, Tanzania, as a study area for evaluating the technical, economic, and social challenges of RWH practices. A storage water level monitoring gauge was used so as to simplify rainwater quantity control and utilization strategy. Basic quality control components such as first flush tank were incorporated so as to reduce the particle load flowing into the storage. Cost reduction strategies such as the one (1) company one (1) community campaign were applied to address the cost implication. To enhance ownership, participatory approach of the beneficiaries in all stages including planning, designing and implementation was adopted. In order to ensure project sustainability, training on how to operate and maintain were provided as well as a maintenance manual to impart a sense of ownership. For the challenges of imparting RWH practices in Tanzania, 19 solutions have been identified and they include provision of RWH manuals, guidelines and regulations, government incentives, and promotion of self-financing initiatives. For developing countries, the study proposes the following strategies: establishing relevant regulations and research centers, enhancing individual and community financial stability, conducting demonstration projects, and increased investment by government on promotion.
\end{abstract}

\section{Keywords}

Community Based Rainwater Harvesting, Rainwater Harvesting Challenges, Rainwater Harvesting Adoption, Rainwater Harvesting Sustainability, Tanzania 


\section{Introduction}

Despite the geographical advantages that Tanzania has, an Eastern African country, recognized for abundant annual renewable water resources of approximately $89 \mathrm{~km}^{3}$ [1] and spatial distribution of the annual rainfall that ranges from less than 400 to higher than $2000 \mathrm{~mm}$, various parts of the country still suffer from water shortages. Low drinking water service coverage, which is around $40 \%$ and $74 \%$ in rural and urban areas, respectively [2]. The major source of water in many parts of the country includes springs, shallow wells, and then boreholes. Regardless of its many advantages, rainwater harvesting (RWH) is one of the least sought sources of water [3]. In a GIS based RWH potential study, [4] established that harvestable rainwater for the medium rainfall (400 $1200 \mathrm{~mm}$ ), high population ( $>100$ persons $/ \mathrm{km}^{2}$ ) rooftop domain ranges from 115.6 to $346.8 \mathrm{~km}^{3}$ (which generally displays high ability to meet daily water demand). But by April 2015, 1862 RWH tanks had been built in 931 villages under the water sector development programme, which is about $9.2 \%$ of villages in Tanzania based on the 2009 statistic of 10,165 villages total in Tanzania mainland [2].

RWH is a potential and sustainable alternative water source to solve water shortage problems, particularly in developing countries [5] [6]. Rainwater quantity can be predicted through modeling as has been demonstrated by several researchers in optimizing storage size [7]. Even though, rainwater quality may deteriorate depending on the type and conditions of collection, delivery, and storage facilities, several simple techniques exist for particle load reduction including use of screens, first flush tanks [8]-[11]. Further, the challenge on investment cost has been addressed through cost reduction strategies, including reduction in construction and material quality; use of local materials, labor and techniques usage [8] [12].

This study aims at: 1) improving sustainability of community based RWH systems; 2) identifying challenges of current RWH practices in Tanzania and suggesting solutions, and 3) recommending strategies to sustainably promote adoption of RWH practices in Tanzania and characteristically similar countries.

\section{Sustainability Consideration of Community Based Rainwater Harvesting Systems}

Recently a RWH demonstration project was implemented at Mnyundo Primary School, a typical rural public primary school located in Mtwara Region, southern Tanzania (Figure 1). The school had no reliable water supply system, and students had to spend their school productive time walking a long distance of up to $2 \mathrm{~km}$ to fetch water. The commonly used unsafe sources of water include river and a communally shared borehole. The major project goal was to ensure that rainwater satisfies the domestic water demand for drinking water purposes. The school was chosen owing to its geographical advantage for technology promotion among school children, community households and teachers. It is fair to note that improving water accessibility for school children within the school premises, provides them with an opportunity to spend most of their productive time focusing on their studies, a fact that would have not been possible before 


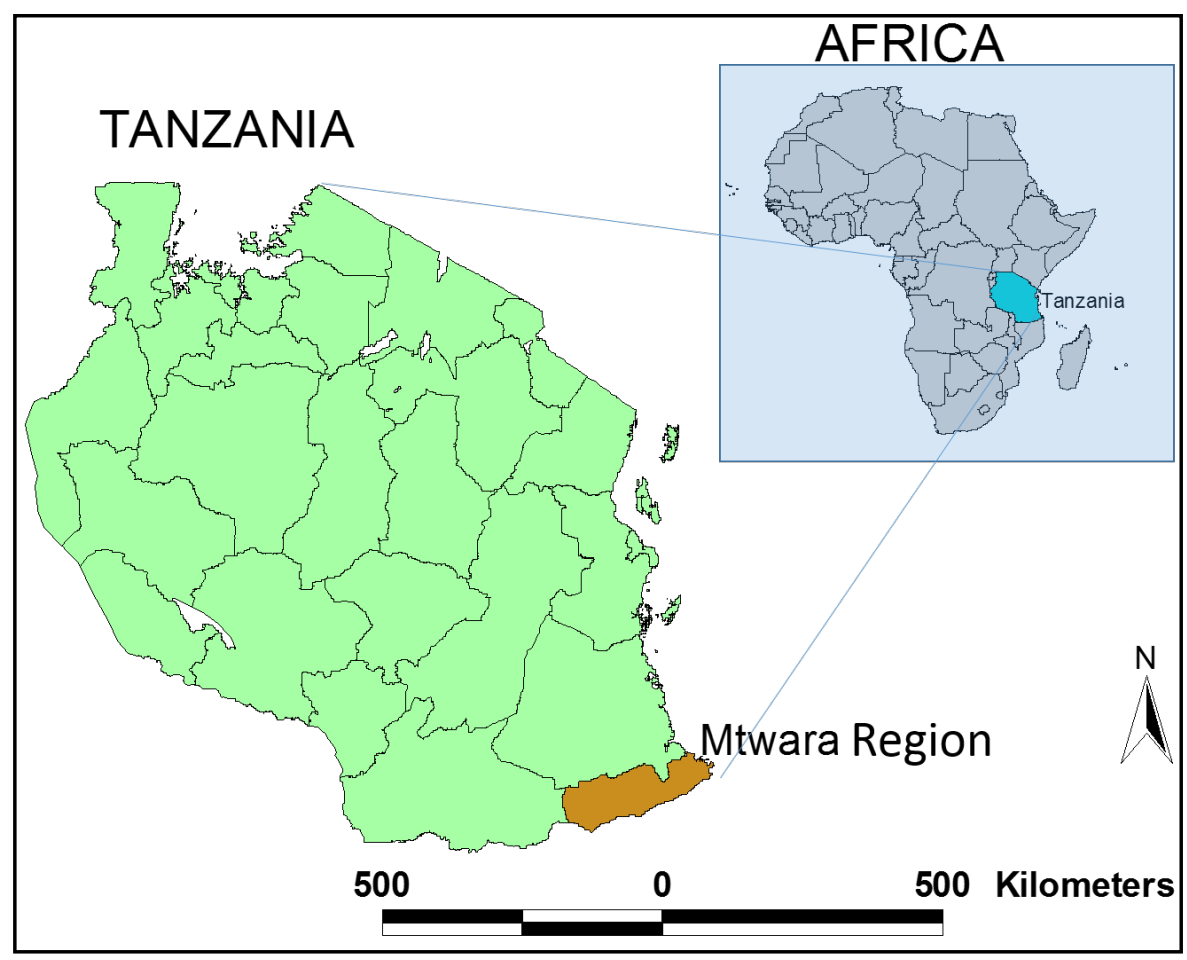

Figure 1. Location map of mtwara region in Tanzania (Modified from [13]).

the project.

Typically, a RWH system is comprised six main parts (Figure 2), including a roof catchment of area $168 \mathrm{~m}^{2}$ for the study area, a treatment system with a coarse screen, the first flush tank, and sedimentation tank. The storage system comprised two $5 \mathrm{~m}^{3}$ plastic tanks, where the first tank (tank 1) was used for sedimentation and the second (tank 2) for storage. Further, a water level gauge was used for monitoring the water level. The development plan of the study project was designed by a team from Seoul National University. Seoul National University Rainwater Research Center (SNURRC) and Korean Society of Civil Engineers financed the project with an investment of US\$ 3600 as part of their corporate social responsibility (CSR) endeavor. The Mtwara District Water Engineer was among the team members involved in the project planning, designing, and execution.

The technical, economic and social innovative ideas were incorporated within the project. Quantity monitoring was improved by making use of a water level gauge attached on the surface of the storage tank. Provision of palatable and safer water for drinking was made possible with the inclusion of simple particle load reduction techniques such as screen, first flush tank for diverting $0.5 \mathrm{~mm}$ of initial rainfall, and settling enhanced with the two $5 \mathrm{~m}^{3}$ tanks in series. The tank 1 in the series is the sedimentation tank and tank 2 is the storage tank which supplies water for the demands. Construction cost was reduced by making use of locally available material, labour and techniques. Further, the financial load on beneficiaries was reduced through the introduction of one (1) company one (1) community (1C1C) campaign, whereby SNURRC 


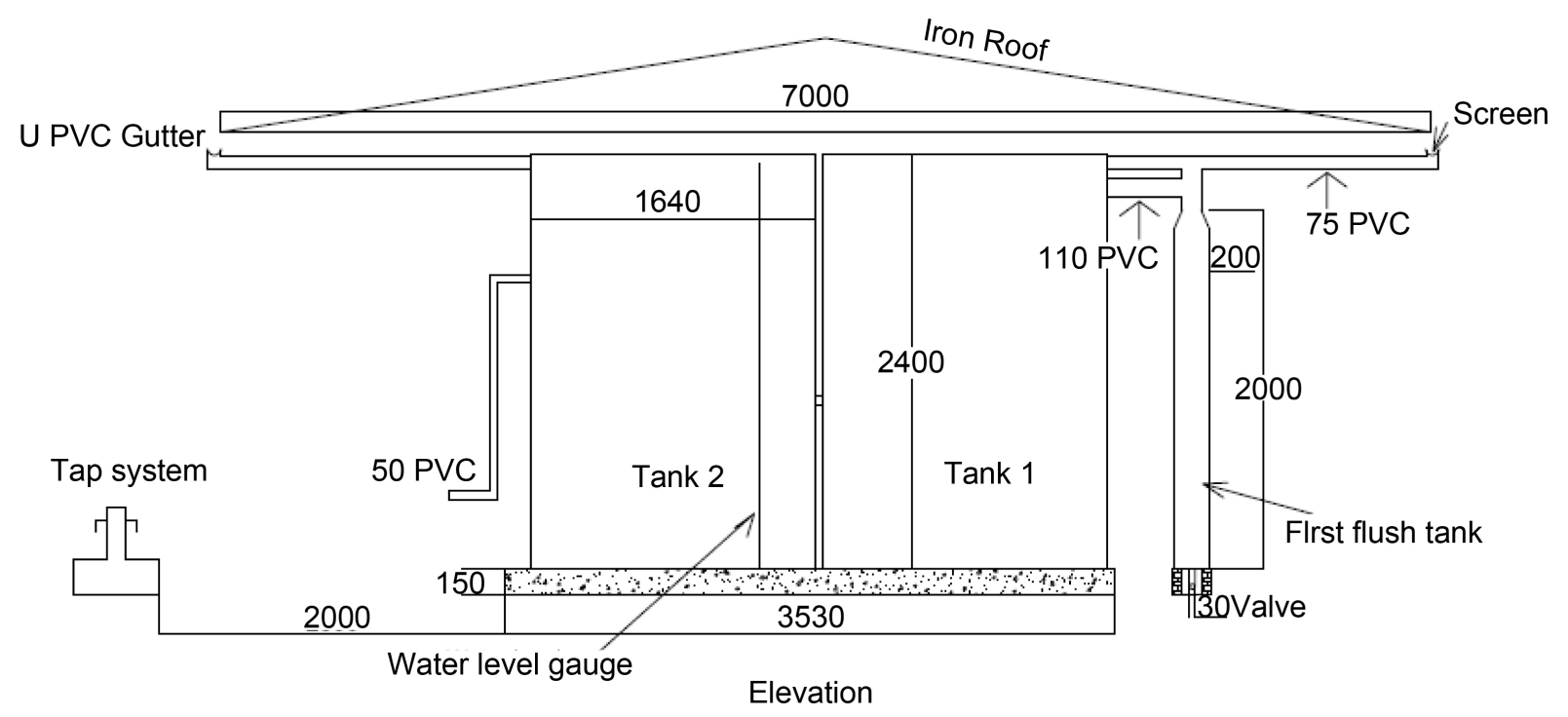

Figure 2. Schematic diagram of Mnyundo primary school rainwater harvesting system.

as a company donated the RWH system to the school as their CSR. As well, local people were fully involved during the planning through to the final implementation stage and also were provided with an operation and maintenance manual. These initiatives had the benefit of, empowering the beneficiaries for operation and maintenance, capacity building, increasing sense of ownership and community spirit. These have been further described in another article by the authors [6]. Moreover, a water level monitoring strategy was introduced through making use of the water level gauge and adopting variable demand operational method. This has been shown to improve performance of the system by ensuring water availability even during the dry season as detailed by the authors [14] [15].

In other studies [16], community-based (CB) RWH has been suggested as an innovative solution for developing countries in Africa and Asia, capable of supplementing CB ground water harvesting current shortcomings, and develop a sustainable drinking water supply system. Through Asian and African case studies, the authors identified 14 innovative solutions for resolving technical, economic, and social problems, which have been barriers to the wide use of CB-RWH. Further, promotional strategies were recommended including having more pilot projects implemented at local levels, and knowledge dissemination in all levels of the educational system.

\section{Challenges and Solutions of Rainwater Harvesting Practices in Tanzania}

Although numerous RWH challenges exist in Tanzania, the common technical, economic and social challenges have been studied. Technically, most RWH storage tanks have problems related to water quantity and quality. The temporal and spatial variable/irregular nature of rainfall during the year has led to its categorization as an uneliable source, most specifically due to rainfall shortages during the dry season. In most 
areas, local rainfall data, which is an essential input data for establishing efficient designs, is quite expensive and not easily accessible. Water quality is affected by sediment accumulation, turbidity due to suspended particles, and even tiny visible insects. Furthermore, technical capacities for developing RWH systems are limited because of limited business opportunities and a lack of approved or adopted technical standards and guidelines. Occasionally, poor design becomes an obstacle to harvesting rainwater for consumption, with experiences of leakage, cracks, and infiltration by contaminants.

Economically, equipment and material costs are high. These initial costs of RWH systems are prohibitive for most individual households. On top of these, low quality workmanship partly contribute to an immature market for rainwater business.

Socially, due to poor water quantity and quality as well as lack of successful demonstration projects, RWH is not highly prioritized as an alternative water supply source. Despite the demonstrations constructed within communities, there are no customized policies or regulations enforcing the adoption nor incentives. There is limited awareness of RWH best management practices. Free donations without any kind of reciprocation from beneficiaries results in reduced commitment to management of the provided system. Moreover, local water committees have accessibility challenges to financial and technical support due to limited recognition within government bodies.

For improvement of RWH practices in the country, 19 solutions have been proposed to address the common problems raised above (Figure 3). With specific guidelines, standards, and regulations in place, the targeted technology potential can be achieved and adoption can be increased. Follow up on implementation of currently passed RWH bylaws as per mandate given to local government authorities (LGAs) is needed. In addition, the remaining LGAs should be encouraged to pass their bylaws. As of May 2015 only 29 out of 168 LGAs had such bylaws in place.

Media involvement, training, and inclusion of technology basics in the education system can serve to boost technology awareness as well as empowerment. Social and financial strategies can allow users to afford their own systems with reduced reliance on donors, and thereby boost their sense of ownership, guaranteeing a system that is operated and maintained well. Government financial support to interested individuals and communities is of paramount importance. This can be through incentives and provision of subsidies.

\section{Strategies for Promotion and Adoption of Rainwater Harvesting in Tanzania}

The Tanzanian National Water Sector Strategy [17] acknowledges that RWH can play a role in offsetting water shortages. However, current promotional efforts through demonstration projects are not enough. There is much to learn from other countries including Germany, Japan, Korea, Australia, with respect to the adoption and promotion of RWH technology, for which attempts including knowledge dissemination, provision of subsidies and incentives, as well as exemption in taxes for RWH facilities have been made. As a way forward for Tanzania, a strategic plan is needed to address issues that 


\section{\begin{tabular}{l|l|l} 
Perspective & Challenges & Solutions
\end{tabular}}

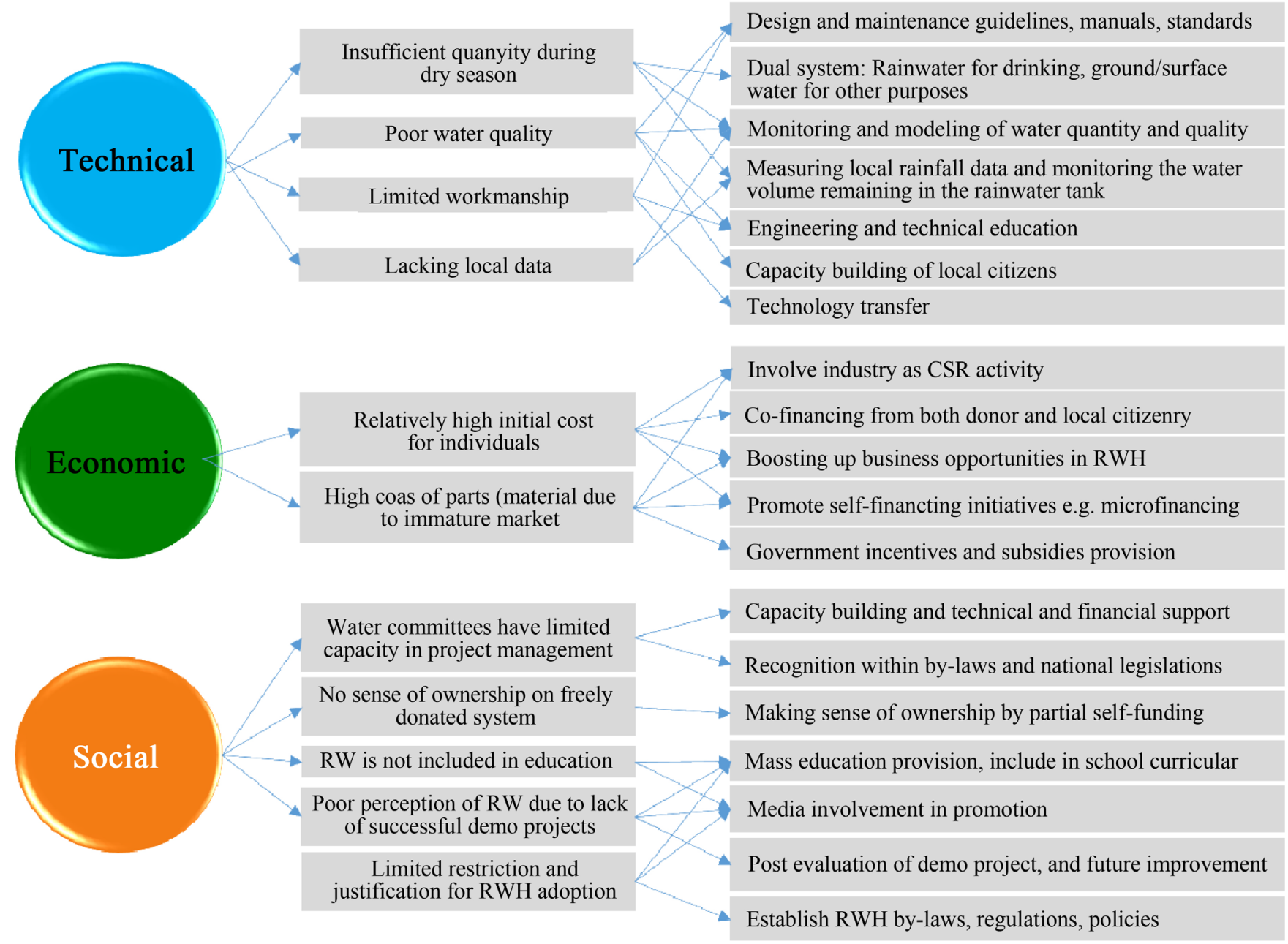

Figure 3. Common challenges and proposed solutions for rainwater harvesting practice improvement in Tanzania.

have been affecting sustainability of water supply projects namely; ownership, maintenance, cost implication, enforcement, research and development, empowerment, and awareness [18].

\subsection{The Need for RWH Regulations}

Specific regulations are imperative for guiding, restricting, and enforcing the adoption and attainment of the targeted technology potential. These should be recognizable at national level. Furthermore, national RWH technology guidelines and standards are vital. Fortunately, the Water Resources Management Act No. 11 of 2009, on page 366, gives citizens the right to establish personal RWH system for domestic purposes within their premises.

Establishment of enabling policies and cost-sharing strategies, including the provision of subsides along with technical know-how and capacity building for promotion of RWH is recommended [19]. To promote urban water harvesting, policies should in- 
clude a mix of incentives and penalties, and that such policy initiatives should be strengthened further through legislation [20].

\subsection{The Need for a Water Research Center}

Existence of a research center would help play the role of exploring, studying, and sustaining a technology. For development and sustainability of a RWH technology, engaging in respective research is essential. For years, a number of agricultural research centers have been active in the country, unlike water-specific ones. As a way forward, to sustain, develop, and address prevailing water supply challenges, it seems imperative to propose the establishment of a water research center as a stand-alone entity, because water is equally important for one's life and welfare. Indigenous knowledge on rainwater harvesting has been in existence since memorial, such knowledge needs to be evaluated and thereafter improved in a sustainable manner.

The center can be affiliated with government sector, universities and colleges, industrial and private sectors, and individuals, for increased efficiency and influence.

\subsection{Enhancing Financial Stability/Support of Individuals and the Community}

For sustaining the application of the technology it is equally important to empower people financially rather than only technically e.g., educate on self-funding and selfsupply initiatives. Therefore, the role of beneficiaries should be increased through various strategies in order to overcome the challenge posed by the cost of RWH construction, and also to dispel the free water attitude and instill a sense of ownership. This would ensure project sustainability in the long run. For instance, in Korea, the Seoul Metropolitan Government passed a regulation that facilitates joint financial contribution from local government, the Donor Company, and volunteers for implementing RWH projects [21].

\subsubsection{Self-Supply Initiatives}

A self-supply initiative is a low cost approach to service delivery, initiated by individual families or groups. This initiative was facilitated while promoting RWH in rural areas of Thailand [22]. Self-supply initiatives can serve as a motivator to external support from the government and the private sector as well, upon seeing internal efforts to improve the standard of living. Moreover, it reduces the reliance on government support. Systems financed under self-supply initiatives have the potential for better maintenance and management. These may include, co-financing, cash/in-kind contributions, labor contributions, and microfinancing.

\subsubsection{C1C Campaign}

In community RWH projects, the involvement and cooperation of the public sector, the community and the private sector is essential. Each entity involvement has a beneficial impact on the project implementation and sustainability. Companies with suitable policies on community outreach activities can perform a 1C1C campaign as a CSR activity 
and gain recognition by the community and the public. This would cause the effective dissemination of technology, and address financial constraints.

\subsection{Implementing Demonstration Projects}

With the advancement in technology, the processes of implementing demonstration projects so as to promote specific technologies are imperative. However, appropriate strategies are required to ensure their acceptability is instilled in communities and facilitate change of individual mindset as they acquire spirit of project ownership within their knowledge and financial comfort zone. A demonstration project should serve as a model for promotional plans, to guide, train, build capacity, and ensure consistency in design and application of the technology. During demonstration, training and capacity building should be provided to engineers, technicians as well as beneficiaries. Construction and maintenance empowerment should be targeted, and adoption and awareness promotion aimed at. Post project evaluation is essential. Moreover, water problems are site specific, it is therefore advised that location for pilot projects should be representative of areas with specific unique rainfall characteristics, topographical and geological conditions [16]. For the case of a country like Tanzania, this includes unimodal and bimodal regimes, mountainous and arid areas. Hence, the targeted technology potential can be achieved.

\subsection{Increasing Investment by Government on Promotion}

Clearly stipulated government roles are essential in ensuring implementation of given advocated technology in community. Countries such as Australia, Germany, India, Japan, in support of RWH practices by individuals and communities, their offering incentives, subsidies, tax exemptions, rebates, and in some countries these are strengthened through legislations [23] [24]. Tanzania government should invest in offering incentives and subsidies to support individual efforts to address their water supply challenges with RWH. In recent years in an effort to boost agricultural production and the livelihood of rural households, the government has been offering farmers subsidies on seeds and fertilizers [25] [26]. Further, the Tanzania Social Action Fund (TASAF) is implementing a productive social safety net, whose subcomponent is conditional cash transfer that targets poor and vulnerable families [27]. The conditions imposed are those of health and education compliance. Similar efforts are proposed towards promoting RWH. Alternatively, RWH can be incorporated as a condition in the TASAF program. People can be advised to use some of the funds provided to install a simple RWH facility for meeting the drinking and cooking demands of the family. A favorable deal/tender can be secured with an engineering company/industry to produce cost effective storage tanks for such a project with TASAF. This would ensure that health is not jeopardized, thereby also impacting education through increased school attendance. Further, with healthy bodies and a relaxed mind, more energy can be invested in economic activities, including agriculture which employs more than $80 \%$ of the population. 


\section{Conclusions}

Mnyundo primary school RWH demonstration project in Tanzania has displayed potential for sustainable community RWH projects, with simple techniques improving on quantity and quality, community involvement in operation and maintenance, and system affordability. This demonstration project serves as a display of how current RWH practice problems can be addressed. Moreover, 19 solutions have been suggested to address identified problems of current RWH practices in Tanzania. These include, having RWH manuals, guidelines and regulations and promoting self-financing initiatives. Hence, with RWH technology community members can address their water supply challenges, water service coverage can be increased, and direct dependence on government finances reduced.

Furthermore, authors recommend on an action plan with the following strategies for improvement in RWH adoption and sustainability in the country:

- Establishment of regulations and research centers,

- Enhancement of individual and community financial stability,

- Implementation of demonstration projects, and

- Investment in RWH promotion by government, and provision of incentives and subsidies.

The various strategies on RWH technology described in the study can be easily adopted and implemented in other regions with similar climatic condition and policies.

\section{Acknowledgements}

This research was supported by Korea Ministry of Environment as Eco-Innovation Project (413-111-008). The authors also acknowledge the partial financial support of KSCE and IRICEE for the demonstration project, and the involvement of the Mtwara District Office in Tanzania.

\section{References}

[1] MoW (2014) The Water Sector Status Report 2014, Marking the End of WSDP Phase I. Water Sector Development Programme. Ministry of Water, Tanzania.

[2] NBS (2011) Tanzania National Panel Survey Report (NPS)-Wave 2, 2010-2011. National Bureau of Statistics, Dar es Salaam, 1-101.

[3] MoW (2014) Simple Querying: Water Point Source Type. Water Point Mapping Tanzania, Ministry of Water. http://wpm.maji.go.tz/?x=T9J8IDBk76zX6dBWO3UHw

[4] Malesu, M., Khaka, E., Mati, B., Oduor, A., Bock, T.D., Nyabenge, M. and Oduor, V. (2006) Mapping the Potentials for Rainwater Harvesting Technologies in Africa: A GIS Overview on Development Domains for the Continent and Nine Selected Countries. Technical Manual No. 7, World Agroforestry Centre (ICRAF), Netherlands Ministry of Foreign Affairs Nairobi.

[5] Temesgen, T., Han, M.Y., Park, H. and Kim, T.I. (2015) Design and Technical Evaluation of Improved Rainwater Harvesting System on a University Building in Ethiopia. Water Science and Technology: Water Supply. http://dx.doi.org/10.2166/ws.2015.085

[6] Mwamila, T.B., Han, M.Y. and Kum, S. (2016) Sustainability Evaluation of a Primary 
School Rainwater Demonstration Project in Tanzania. Journal of Water, Sanitation and Hygiene. http://dx.doi.org/10.2166/washdev.2016.186

[7] Mun, J.S. and Han, M.Y. (2012) Design and Operational Parameters of a Rooftop Rainwater Harvesting System: Definition, Sensitivity and Verification. Journal of Environmental Management, 93, 147-153. http://dx.doi.org/10.1016/j.jenvman.2011.08.024

[8] Thomas, T.H. and Martinson, D.B. (2007) Roofwater Harvesting: A Handbook for Practitioners. IRC International Water and Sanitation Centre, Delft.

[9] Han, M.Y. and Mun, J.S. (2007) Particle Behaviour Consideration to Maximize the Settling Capacity of Rainwater Storage Tanks. Water Science and Technology, 56, 73-79. http://dx.doi.org/10.2166/wst.2007.778

[10] Amin, M.T., Kim, T.I., Amin, M.N. and Han, M.Y. (2013) Effects of Catchment, First Flush, Storage Conditions, and Time on Microbial Quality in Rainwater Harvesting Systems. Water Environment Research, 85, 2317-2329. http://dx.doi.org/10.2175/106143013X13706200598433

[11] Coombes, P. (2015) Discussion on "Influence of Roofing Materials and Lead Flashing on Rainwater Tank Contamination by Metal" by Magyar M.I., Ladson, A.R., Daiper, C., and Mitchell, V.G. 2014. Australian Journal of Water Resources, 18, 71-83.

[12] Kihila, J. (2014) Rainwater Harvesting Using Ferro Cement Tanks an Appropriate and Affordable Technology for Small Rural Institutions in Tanzania. International Journal of Civil and Structural Engineering, 3, 332-341.

[13] PMORALG (2010) Monitoring Local Government Sectors and Performance. http://www.pmoralg.go.tz/lginformation/perfmap1.php

[14] Mwamila, T.B., Han, M.Y., Kim, T.I. and Ndomba, P.M. (2015) Tackling Rainwater Shortages during Dry Seasons Using a Socio-Technical Operational Strategy. Water Science \& Technology: Water Supply, 15, 974-980.

[15] Mwamila, T.B., Ndomba, P.M. and Han, M.Y. (2016) Performance Evaluation of Rainwater Harvesting Systems and Strategies to Mitigate Water Shortage in Dry Seasons: A Case Study of Mnyundo School, Tanzania.

[16] Nguyen, C., Kim, Y.K., Han M.Y., Kabubi, J. and Sohn, H.J. (2016) Community-Based Rainwater Harvesting (CB-RWH) to Supply Drinking Water in Developing Countries: Lessons Learned from Case Studies in Africa and Asia. Water Science and Technology. Water Supply, In Press.

[17] MoWI (2008) National Water Sector Development Strategy: 2006 to 2015. Ministry of Water and Irrigation, Tanzania.

[18] Mwamila, T.B. (2016) Rainwater Harvesting Potential and Management Strategies for Sustainable Water Supply in Tanzania. PhD Thesis, Department of Civil and Environmental Engineering, Seoul National University, Seoul.

[19] UNEP (2009) Rainwater Harvesting: A Lifeline for Human Well-Being. United Nations Environment Programme and Stokholm Environment Institute.

[20] UN-Habitat (2005) Rainwater Harvesting and Utilisation. Blue Drop Series, Book 1: Policy Makers. United Nations Human Settlements Programme (UN-HABITAT), Nairobi.

[21] Han, M.Y. and Park, J. (2009) Innovative Rainwater Harvesting and Management in the Republic of Korea. Consulting Meeting for Development of Guidelines for Eco-Efficient Water Infrastructure, Seoul, 30-31st March 2009.

[22] Lockwood, H. and Smits, S. (2011) Supporting Rural Water Supply Moving towards a Service Delivery Approach. Practical Action Publishing Ltd, IRC International Water and Sanitation Centre and Aguaconsult. 
[23] JFS (2014) Let's Use Rainwater! Recent Trends in Rainwater Use in Japan. Japan for Sustainability, Biodiversity/Food/Water: 24 August 2014.

http://www.japanfs.org/en/news/archives/news_id035023.html

[24] Rainwaterharvesting.Org. International Water Harvesting and Related Financial Incentives. http://www.rainwaterharvesting.org/policy/legislation_international.htm

[25] Baltzer, K. and Hansen, H. (2011) Agricultural Input Subsidies in Sub Saharan Africa. Evaluation Study 2011/2, Ministry of Foreign Affairs Denmark. http://www.oecd.org/derec/49231998.pdf

[26] Malhotra, K. (2013) National Agricultural Input Voucher Scheme (NAIVS 2009-2012), Tanzania: Opportunities for Improvement. Policy Research for Development (REPOA). http://www.repoa.or.tz/documents/REPOA\%20BRIEF\%2040.pdf

[27] TASAF (2015) Conditional Cash Transfer. http://www.tasaf.org/index.php?option=com_content\&view=article\&id=69

\section{Submit or recommend next manuscript to SCIRP and we will provide best service} for you:

Accepting pre-submission inquiries through Email, Facebook, LinkedIn, Twitter, etc. A wide selection of journals (inclusive of 9 subjects, more than 200 journals)

Providing 24-hour high-quality service

User-friendly online submission system

Fair and swift peer-review system

Efficient typesetting and proofreading procedure

Display of the result of downloads and visits, as well as the number of cited articles

Maximum dissemination of your research work

Submit your manuscript at: http://papersubmission.scirp.org/ 